\title{
PROCEEDINGS OF THE ALL INDIA CONFERENCE ON RESEARCH IN REPRODUCTION AND FERTILITY CONTROL
}

\author{
Organized by \\ Indian Council of Medical Research \\ and \\ Indian Society for Study of Reproduction \\ and Endocrinology \\ Held in Bombay, February 1970
}

Biochemical studies with human semen. I. A correlative study of some constituents with the count and motility of spermatozoa. R. P. Das and Somnath Roy, Medical Education and Research Division, Central Family Planning Institute, New Delhi-16, India.

The initial fructose levels in human semen appear to show an inverse relationship with sperm count. The total cholesterol concentration, however, shows a biphasic pattern; from azoospermia to the count of $60 \mathrm{million} / \mathrm{ml}$, it registers a progressive fall. Ascorbic acid and neuraminic acid concentrations do not show any definite pattern of fluctuation, although the levels of the latter are elevated in the higher count groups. The acid and alkaline phosphatase activities appear to be directly correlated with sperm count. The semen of individuals becoming azoospermic after vasectomy contains higher levels of ascorbic acid, neuraminic acid and cholesterol compared to the semen of other intact azoospermic patients, and this difference is most evident with ascorbic acid. On the other hand, the fructose concentration and the acid phosphatase activity are lower in the semen of vasectomized azoospermic individuals; this difference is more pronounced with the latter.

The levels of these constituents do not appear to show any correlation with sperm motility except that, for two individuals whose semen contained mostly dead spermatozoa, the concentration of ascorbic acid was very low.

Hormonal influences on the maltase activities of testis and prostate of rats. K. P. Gunaga, A. R. Sheth and Shanta S. Rao, Division of Fundamental Research, Institute for Research in Reproduction, Jehangir Merwanji Street, Parel, Bombay-12, India.

It was observed that maltase is present in significant amounts in rat testes as well as in the dorsolateral prostate. The experiments on intact rats showed that unlike prostatic maltase, testicular maltase was not affected by the administration of testosterone or its active metabolite dihydrotestosterone. Studies on the effect of endogenous or exogenous gonadotrophins in the rat have shown that maltase activity of the dorsolateral prostate, but not testicular maltase, is dependent on pituitary factors. 
Variations in testicular cholesterol following long-term treatment with oestradiol. A. K. Sivashankar and M. R. N. Prasad, Department of Zoology, University of Delhi, Delhi-7, India.

Variations in cholesterol in the testis have been studied in adult male rats following long-term treatment with oestradiol-17- $\beta$ and during a 5-week recovery period after the withdrawal of treatment. Testicular cholesterol concentration is maximal at the end of 60 days of treatment with $12.5 \mu \mathrm{g} /$ day of oestradiol-17- $\beta$ and decreases to control levels after 5 weeks of recovery. The variations in testicular cholesterol concentration show an inverse relationship to the pattern of recovery of pituitary FSH and LH. The significance of these relationships is discussed.

Temporary sterilization of the male (human subject) by an intravasal contraceptive device (IVCD). M. L. Kothari and D. S. Pardanani, Department of Anatomy and Surgery, Seth G. S. Medical College and K. E. M. Hospital, Parel, Bombay-12, India.

The present procedure aims at producing a subfertile sperm count by obturating the lumen of the vas deferens by a thread (IVCD), made of non-reactive, synthetic material, which can be easily removed to restore fertility.

The clinical experience of the authors with ten cases is reported.

The follow-up periods range from 4 to 36 weeks. Some patients showed considerable reduction in sperm count, while others showed a moderate reduction. Regardless of the sperm count reduction, all have been allowed to have normal sexual life. So far there is not a single reported conception. This is probably due to the fact that, apart from the reduction in the count, the characteristic of the spermatozoon is altered by the presence of the Silastic filament.

Effects of partially purified salmon pituitary gonadotrophin on re-initiation of spermatogenesis in the long-term hypophysectomized catfish, Heteropneustes fossilis. B. I. Sundararaj, S. K. Nayyar, T. G. Anand and E. M. Donaldson, Department of Zoology, University of Delhi, Delhi-7, India.

The testes were completely regressed and spermatogenesis was arrested at the level of spermatogonia in the 237-day hypophysectomized control catfish. Administration of daily doses $(0 \cdot 1 \mu \mathrm{g}, 1 \mu \mathrm{g}, 10 \mu \mathrm{g}$ and $100 \mu \mathrm{g})$ of salmon gonadotrophin ( $\mathrm{SG}$ ) for 30 days produced a dose-dependent response in the testes. A dose of $0.1 \mu \mathrm{g} \mathrm{SG}$ resulted only in the formation of lumina in the seminiferous tubules without re-initiating spermatogenesis, whereas treatment with $1 \mu \mathrm{g}$ of SG qualitatively restored spermatogenesis in the tubules. Following treatment with $10 \mu \mathrm{g}$ of SG, spermatogenesis was both qualitatively and quantitatively restituted. A dose of $100 \mu \mathrm{g}$ of SG not only restored spermatogenesis qualitatively and quantitatively but also induced repeated spermiation. Treatment with $10 \mu \mathrm{g}$ of ovine LH produced a spermatogenic response comparable to that induced by $1 \mu \mathrm{g}$ of SG. Testosterone $(100 \mu \mathrm{g})$ qualitatively restored spermatogenesis; this effect was slightly better than that produced by 
$1 \mu \mathrm{g}$ of SG. The results indicate that the testes of the catfish are much more sensitive to salmon gonadotrophin than to ovine LH. The possible mechanisms involved are discussed.

Morphology of spermatozoa in relation to fertility of animals. D. P. MukHerjee, Division of Animal Genetics, Indian Veterinary Research Institute, Izatnagar, India.

The paper reviews the work of the author and his associates on the effect of breed, body weight, seasons, gaseous composition of the inspired air and blood circulation on the morphology and fertilizing capacity of spermatozoa of animals, including farm animals.

Dynamics of phospholipid metabolism in the sexual segment and kidney of the Indian house lizard, Hemidactylus flaviviridis Ruppell. P. R. K. Reddy, M. R. N. Prasad and U. K. Misra, * Department of Zoology, University of Delhi, Delhi-7, India, and *Department of Biochemistry, V. P. Chest Institute, University of Delhi, Delhi-7, India.

The incorporation of radioactive inorganic orthophosphate into the sexual segment and kidney phospholipids was studied at various time intervals in sexually active and regressing lizards and following castration and testosterone administration. The incorporation of the label into total phospholipids of the sexual segment as well as the kidney is gradual and reaches a peak at $12 \mathrm{hr}$ followed by a gradual decrease at later time intervals. Among the individual phospholipids, the phosphatidic acid + polyglycerol phosphatide and phosphatidyl inositol + phosphatidyl serine fractions incorporate the label rapidly during the first $30 \mathrm{~min}$, while the phosphatidyl choline and phosphatidyl ethanolamine fractions show the heavy label at later intervals. The pattern of incorporation is similar in the phospholipids of the sexual segment and of the kidney but the intensity of incorporation in the sexual segment is higher during the active season than in the regressing season. Castration reduces the uptake of the precursor by the sexual segment; in such animals, testosterone stimulates the turnover of various phospholipids to a level comparable to that seen in the sexual segment during the active season.

In the kidney, the pattern and intensity of incorporation of the precursor into phospholipids is unchanged during the active and regressing seasons and following castration and testosterone treatment.

Rapid early incorporation of the precursor into the phosphatidic acid fraction suggests its obligatory rôle in the biosynthesis of other complex lipids. The differential stimulation of the uptake of the label by sexual segment phospholipids is clear evidence of the selective action of testosterone on this target organ.

On the characterization of ovine pituitary gonadotrophins. S. DURaiswami and G. SReemathi, Department of Zoology, Delhi University, Delhi-7, India.

It is generally agreed that preparations of pituitary gonadotrophins with high 
potency are heterogeneous by physico-chemical criteria, while less potent material is apparently homogeneous. The present study is based on the hypothesis that more than one molecular species of gonadotrophin, be it FSH or LH, may exist in any crude extract of the pituitary and that these may differ not only with respect to their chemical structure but also in terms of their characteristic biological activities. A series of studies has been designed to analyse the nature and distribution of gonadotrophic activity in crude extracts of ovine pituitaries, obtained by different procedures, using gel filtration on Sephadex G-100 as a screening technique to enable a correlation of chemical composition with biological activity. It has been shown in an earlier contribution that gel filtration on Sephadex G-100, under specified conditions, constitutes a valuable analytical tool in studies on fractionation and characterization of pituitary gonadotrophins.

On this basis, three different batches of ovine pituitary extracts prepared by a modified Koenig-King procedure were examined by gel filtration on Sephadex G-100. The data show that while the same number of components, characterized by their partition coefficients based on $E_{280}$ and $E_{260} \mathrm{~m} \mu$, are present in all three extracts, their relative proportions, for the same amount of total protein, are variable. The presence, in one of the batches, of multiple components with FSH activity was correlated with multiple maxima in the curve for the distribution of sialic acid. These and related data based on analysis by starch gel and polyacrylamide gel electrophoresis are discussed from the point of view of microheterogeneity of ovine pituitary gonadotrophins and in relation to recent data on human chorionic gonadotrophin.

Two novel developments in the biochemistry of androgen action. H. A. Williams-Ashman, Ben May Laboratory for Cancer Research and Department of Biochemistry, University of Chicago, Illinois 60637, U.S.A.

The cervix and fertility control. E. S. E. HAFEz, Reproduction Laboratory, Department of Animal Sciences Washington State University, Pullman, Washington, U.S.A.

The mammalian cervix plays a major rôle in reproduction. Species differ remarkably in cervical anatomy and cytology. Endogenous and exogenous ovarian hormones influence the biophysical and biochemical characteristics of cervical mucus. Mucus characteristics, in turn, affect the pattern of transport and distribution of spermatozoa in the female reproductive tract. The biophysical and biochemical properties of cervical mucus are used to evaluate ovarian function, to confirm ovulation or anovulation, to estimate the optimal time for conception, and to assess the adequacy and normality of cervical secretions. Exogenous steroids may be used to develop new contraceptive methods based on shortening the survival time of spermatozoa. It may also be possible to stimulate the cervix to produce antibodies locally in order to induce voluntary infertility as a method of contraception. The cervical factor in reproductive failure is important; it includes congenital anomalies, mechanical factors, endocrine imbalances, abnormal cervical mucus and infections. It is frequently related to such obstetrical and gynaecological syndromes as 
abortion, difficult or prolonged delivery; post-partum and post-abortum curettage; and electrocauterization, amputation or conization of the cervix. Areas of future research are outlined.

Time sequences of action of oestrogen on nucleic acid and protein synthesis in the uterus and blastocyst during delayed implantation in the rat. Suresh Mohla, C. M. S. Dass and M. R. N. Prasad, Department of Zoology, University of Delhi, Delhi-7, India.

The time sequence of the action of oestrogen on the incorporation of $\left[{ }^{3} \mathrm{H}\right]$ cytidine, $\left[{ }^{3} \mathrm{H}\right]$ thymidine and $\left[{ }^{3} \mathrm{H}\right]$ phenylalanine in the uterus and blastocyst during delayed implantation in the rat was studied autoradiographically. (1) Oestrogen enhances the synthesis of RNA in the blastocyst within $1 \mathrm{hr}$ and this is maintained up to $18 \mathrm{hr}$; the uptake is seen in the nucleus as well as in the cytoplasm. Synthesis of RNA increases in the uterus within $3 \mathrm{hr}$ of oestrogen treatment, reaches a peak by $6 \mathrm{hr}$, is maintained up to $12 \mathrm{hr}$ and declines by $18 \mathrm{hr}$; the uptake is predominantly located in the nuclei. (2) Oestrogen also increases uterine protein synthesis within $6 \mathrm{hr}$, reaching a peak by $12 \mathrm{hr}$ and is maintained up to $18 \mathrm{hr}$. (3) Oestrogen causes enhanced DNA synthesis in the blastocyst by $42 \mathrm{hr}$, while the uterus is still unresponsive at this time. Synthesis of DNA in the uterus is initiated at about $50 \mathrm{hr}$ after oestrogen treatment. (4) It has been shown that oestrogen has a differential time sequence of action on the uterus and blastocyst. Further studies on the early action of oestrogen will be discussed.

Fate of $\left[6,7-{ }^{3} \mathrm{H}\right]$ norethynodrel in women. K. Murugesan, V. Hingorani, B. K. Anand and K. R. Laumas, Reproductive Biology Research Unit, All India Institute of Medical Sciences, New Delhi-16, India.

After an intravenous injection of $\left[6,7{ }^{3} \mathrm{H}\right]$ norethynodrel, its disappearance and metabolic clearance rate, its uptake in the uterus, subcellular distribution and cytoplasmic protein binding were studied.

The disappearance of radioactive norethynodrel and its metabolites in the plasma of women after an intravenous injection showed that there is an initial rapid disappearance of radioactivity (half-life $76 \mathrm{~min}$ ). This is followed by a slower rate of disappearance of radioactivity with a half-life of about $45 \mathrm{hr}$.

The results could be analysed on the basis of a two-compartment model to describe the metabolism and disappearance of $\left[6,7-{ }^{3} \mathrm{H}\right]$ norethynodrel. The metabolic clearance rate is found to be 30 litres/day.

The uptake studies of $\left[6,7-{ }^{3} \mathrm{H}\right]$ norethynodrel in the uterus showed that the radioactivity is gradually concentrated in the endometrium. The molar concentration was found to be of the order of $10^{-9} / \mathrm{kg}$ tissue. The subcellular localization of radioactivity in the endometrium revealed that $60 \%$ of radioactivity is localized in the $105,000-\mathrm{g}$ supernatant and $30 \%$ in the nuclear fraction. The binding of norethynodrel to cytoplasmic protein was also studied. The very long half-life of norethynodrel may be due to the carrier proteins in plasma. Equilibrium dialysis experiments showed that $87 \%$ of norethynodrel is bound to plasma proteins. The plasma proteins involved in the retention and 
binding of norethynodrel were identified on a DEAE-cellulose column. The results showed that $\alpha$-globulin and albumin are the two main fractions which bind norethynodrel.

The effect of an intrauterine contraceptive device on the mast cell content of the human myometrium: a preliminary report. A. DAss, S. Bhagat, S. Arora and R. K. SAnyal, Maulana Azad Medical College and Associated Hospitals, New Delhi, India.

Mast cells in the human myometrium did not show significant changes either quantitatively or morphologically in the different phases of the menstrual cycle or when studied in different patterns of dysfunctional bleeding.

Significant reduction in the mast cell population of the uterine muscle occurred after insertion of the intrauterine device irrespective of the clinical condition.

The possible cause of this universal reduction is discussed.

Biosynthesis of proteins in human placenta from normal and toxaemic pregnancies. S. A. Rahman, P. K. Malkani, V. Hingorani and K. R. Laumas, Reproductive Biology Research Unit and Department of Obstetrics and Gynaecology, All India Institute of Medical Sciences, New Delhi, India.

The earlier work of Koshti, Malkani \& Laumas (1968) and Laumas, Malkani, Koshti \& Hingorani (1968) showed that the conversion of various androgenic precursors to oestrogens by placental microsomes was lower during toxaemia than in the normal placenta. This was possibly due to either a defect or lack of the microsomal enzymes needed for the aromatization of these precursors. The aim of the present study was to investigate the possible defect in the aromatization reaction in the toxaemic placenta by studying the concentration of RNA, DNA and protein and the incorporation of ${ }^{14} \mathrm{C}$ protein hydrolysate into these components of various subcellular fractions of normal and toxaemic placentae.

The concentration of DNA and protein per gram of placental tissue and the $\mathrm{DNA} /$ protein ratio were found to be lower, whereas the $\mathrm{RNA} /$ protein ratio tended to increase in the toxaemic placenta as compared with the normal one. The total incorporation of ${ }^{14} \mathrm{C}$ protein hydrolysate into RNA, protein and lipid per gram of tissue was also lower in the toxaemic placenta. Among the various subcellular fractions, the microsomal fraction of the toxaemic placenta was found to have a lower concentration of RNA and protein, whereas only the protein content was lower in the $\mathrm{pH} 5$ enzyme precipitate. The relative percentage distribution of RNA decreased in the mitochondrial and microsomal fractions of the toxaemic placenta but that of protein was lower in the microsomal and $\mathrm{pH} 5$ enzyme precipitate fractions.

The incorporation in vitro of ${ }^{14} \mathrm{C}$ protein hydrolysate into RNA, protein and lipid was significantly lower in the microsomal fraction of the toxaemic as compared with the normal placenta. The incorporation of radioactivity was also lower in the other subcellular fractions of the toxaemic placenta but this was not significant. In the cell-free system, incorporation of ${ }^{14} \mathrm{C}$ protein hydro- 
lysate into RNA and protein increased with time in both groups of placentae but during toxaemia it appeared to be lower at various time intervals.

These observations lead to the conclusion that, in the toxaemic placenta, the synthesis of DNA is so affected that it alters the enzyme synthesis needed for protein synthesis and for the aromatization reaction.

\section{REFERENCES}

Koshti, G. S., Malkani, P. K. \& Laumas, K. R. (1968) Indian F. Physiol. Pharmac. 12, 8.

Laumas, K. R., Malkani, P. K., Koshti, G. S. \& Hingorani, V. (1968) Am. J. Obstet. Gynec. 101, 1063.

Biological effects of ovulation-inducing drugs. H. D. TAUBERT, Abteilung für gynakologische Endokrinologie, Universitäts-Frauenklinik, Frankfurt am Main, Germany.

7. Reprod. Fert. (1971) 25, 1.

Gurrent concepts on the regulation of ovulation and corpus luteum function. Virendra B. Mahesh, Department of Endocrinology, Medical College, Georgia, U.S.A.

In an attempt to re-evaluate the rôle of gonadotrophins in the ovarian cycle, the pituitary content of FSH and LH was measured on the day of pro-oestrus in pubertal and adult cycling Holtzman rats. A remarkable decrease was found in FSH and LH during the 'critical ovulatory period' indicating secretion of both hormones. To investigate further whether the secretion of FSH at this time has any physiological rôle, hamsters were injected with a mixture of anti-rsH and LH antiserum or anti-LH antiserum during the critical ovulatory period. The mixture of anti-FSH and LH blocked ovulation whereas anti-LH did not. These experiments indicate that FSH may play a significant rôle in the rupture of the mature Graafian follicle. This was confirmed by obtaining ovulation in hamsters with mature follicles by injecting small quantities of FSH in the presence of a liberal excess of anti-LH. Preliminary evidence suggests that the corpus luteum thus produced in the absence of LH may not secrete progesterone and therefore a synergistic rôle of the two hormones may be physiologically necessary.

Radioimmunoassays for FSH and LH in human serum also reveal a FSH peak coinciding with the midcycle LH peak. Women showing a decreased or absent FSH peak at this time either do not ovulate or have very short luteal phases. Similar observations were made in the anovulatory women treated with clomid. The rôle of prolactin in the ovarian cycle is also discussed.

Action of cyclic AMP in vitro on the uptake and incorporation of radioactive precursors into RNA and proteins in rat uterus. SHAIL K. Sharma, Swatantra K. Jain and G. P. Talwar, Department of Biochemistry, All India Institute of Medical Sciences, New Delhi, India.

Oestradiol causes marked proliferation of the uterine tissue. During the last few years various hypotheses have been advanced to explain the mode of action 
of this hormone, one being that oestradiol-induced changes may be mediated by cyclic AMP. We have shown that cyclic AMP in vitro stimulates uridine incorporation into RNA and incorporation of amino acids into proteins. The increase in the synthesis of RNA and proteins in the uterus by cyclic AMP bears a direct relation to the expansion of the pool size of these precursors in the initial phase. On prolonged incubation, however, the relative specific activity increases, suggesting the activation of the transcription process. This rise in the synthesis of RNA in the early and late phases is not prevented by cycloheximide and does not appear to require the synthesis of proteins. Cyclic AMP primes the tissue in the first 5 to 15 min of preincubation, and its continuous presence in the medium is not required.

Lead haematoxylin-positive cells in the hypophysis of the musk shrew, Suncus murinus L. (Insectivora). D. R. NAIK and G. J. Dominic, Department of Zoology, Banaras Hindu University, Varanasi 5, India.

Lead haematoxylin $(\mathrm{PbH})$-positive cells in the hypophysis of normal, castrated, castrated and androgen-administered, unilaterally adrenalectomized, and Metopirone-treated musk shrew were investigated by employing a number of other staining techniques. In addition to the $\mathrm{PbH}$-positive cells found in the pars intermedia (and occasionally in the pars tuberalis and the pars nervosa), two morphologically distinct types of $\mathrm{PbH}$-positive cells were identified in the pars anterior, of which one responded to castration and the other did not. Neither type of $\mathrm{PbH}$-positive cells in the pars anterior responded to adrenocortical deficiency. The cells which responded to adrenalectomy and Metopirone administration (obviously the corticotrophs) were $\mathrm{PbH}$-negative and had dispersed erythrosinophilic granules in the cytoplasm. It is postulated that the $\mathrm{PbH}$-positive cells which responded to castration are gonadotrophs (probably LH cells). The $\mathrm{PbH}$-positive cells in the pars intermedia and the second type of $\mathrm{PbH}$-positive cells in the pars anterior did not respond to any of the experimental treatments. The nature and possible significance of these cells are discussed in the light of available literature.

Effect of gonadal hormones on electrical activity of brain in adult monkeys. H. K. Kang, Baldev Singh, B. K. Anand and G. S. Chhina, Department of Physiology, All India Institute of Medical Sciences, Nere Delhi, India.

The investigations were carried out to determine the effect of gonadal hormones in adult rhesus monkeys on the EEG activity and evoked responses. The influences of stimulation of genital afferents on the electrical responses of the brain were also studied to find out changes in the responses of different areas of brain as a result of exciting the genital organs. The EEG responses were recorded in conscious monkeys with the help of bipolar electrodes implanted stereotaxically on a ten channel Grass Electroencephalograph, Model 6. A control EEG record was taken which was followed by the injection of $0.4 \mathrm{mg}$ testosterone propionate given daily in the forenoon for 7 days and recordings repeated for 2 to $3 \mathrm{hr}$ following the injection. The procedure was repeated for 7 to 10 days. In each animal, the effect of genital stimulation was observed on 
the EEG both before and after the injection of hormone. Before killing, the animals were anaesthetized with chlorlose and Nembutal a half dose of each and the pudendal nerve was exposed. The responses evoked were recorded through the EEG electrodes following stimulation of the pudendal nerve, using square wave pulses of $0.02 \mathrm{msec}$ duration, $3 \mathrm{~V}$ and a frequency of 10 per sec. The evoked responses, when obtained, were repeated following the injection of testosterone propionate. The administration of the hormone gradually tended to produce an increased tendency for spindle activity and slow waves in the preoptic area, posterior hypothalamus, cingulate gyrus and hippocampus. Genital stimulation further increased the amount of spindle activity and slowing.

The evoked responses were obtained from the preoptic area, the ventromedial nucleus of the hypothalamus and the posterior hypothalamus as well as the sensory cortex. The intravenous injection of testosterone propionate, however, produced the changes in the responses from the preoptic and posterior hypothalamus. The hormones therefore seemed to produce changes in the electrical responses of different parts of the brain by their effects on hypothalamic and limbic structures, which are involved in the satiety and 'need' state of the sex drive.

Light and electron microscope studies on the site of action of Enavid in the hypothalamus of the rhesus monkey. M. BHutani and T. C. Anand Kumar, Departments of Physiology and Anatomy, All India Institute of Medical Sciences, New Delhi, India.

This report describes the preliminary results of light and electron microscope studies on the hypothalamus of adult female monkeys treated with Enavid. The monkeys were obtained from local animal suppliers, kept in cages and their menstrual history recorded for about 6 months; only those animals whose menstrual history showed a regular $28+3$ day cycle and which showed freshly formed corpora lutea at laparotomy performed during the mid-cycle or the premenstrual period, were used for the experimental studies. The animals were given Enavid orally, at a dose of $1 \mathrm{mg}$ per day, from the 5th to the 24th day of the menstrual cycle. The drugs were withdrawn on the 25th day; this was followed by menstruation on the 28th day. Examination of the ovaries at laparotomy during the mid-cycle and towards the end of the period of drug administration showed that the animals did not ovulate after treatment with Enavid. The animals were killed on the 16 th day of medication after administering the drugs for one, three or six cycles. Suitable controls were also taken for comparison.

In a recent publication, it has been stated that the bulbous projections of the tanycyte ependyma, lining a circumscribed area of the third ventricle in the anterior hypothalamus, showed cyclic changes in relation to the menstrual cycle; they were well developed during the preovulatory phase of the menstrual cycle and regressed during menstruation. Changes in the size of the bulbous projections were also observed in experimental animals after ovariectomy and in ovariectomized animals given exogenous sex hormones. On the basis of these and other experimental evidence, it has been suggested that the tanycyte 
ependyma may, in some way, be involved in the hypothalamic regulation of reproduction.

Our preliminary investigations on monkeys treated with Enavid have shown that the bulbous projections in the tanycyte ependyma regress after treatment with the oral contraceptive. The significance of this and other findings are discussed.

Effects of steroids, pituitary inhibitor or pituitary implants on ovarian compensatory hypertrophy in adrenalectomized, hemispayed albino rats. Malathi E. A. D'Souza and M. Appaswamy Rao, Department of Zoology, Karnatak University, Dharwar-3, India.

The effects of adrenalectomy and administration of saline, steroids, methallibure (a pituitary inhibitor) or pituitary homografts on ovarian compensatory hypertrophy in hemispayed rats are studied. Significant hypertrophic response of the ovary is seen 7 days after hemicastration. Adrenalectomy abolishes this compensatory hypertrophic response of the ovary in hemispayed rats. Saline treatment rectifies this inhibition indicating that adrenalectomy reduces the ovarian response to pituitary gonadotrophins, probably due to the electrolyte imbalance in the body fluid. Of all steroids, oestradiol-17 $\beta$ and 19-nortestosterone are potent blockers of ovarian growth in adrenalectomized, hemispayed rats treated with saline, indicating that the blocking effects of these steroids on ovarian growth in hemispayed rats is probably mediated through the pituitary, but not through the adrenals. Even small doses of methallibure, a pituitary inhibitor, which is ineffective in hemispayed rats, retards the ovarian growth in adrenalectomized, hemispayed rats treated with saline. Pituitary homografts in adrenalectomized, hemispayed rats maintain the ovarian compensatory hypertrophy even in the absence of saline treatment. It is concluded that adrenalectomy reduces the ovarian growth response to pituitary gonadotrophins, probably due to electrolytic imbalance of the body fluid initially and, later, affects the pituitary gonadotrophin secretion through the ovary.

Changes in the pituitary FSH and LH levels during the oestrous cycle in the Indian water buffalo. S. P. Agarwal and N. G. Buch, Reproductive Biology Research Unit, Institute of Agriculture, Anand, Gujarat, India.

Thirty-seven mature, cycling buffalo heifers were slaughtered to study the FSH and LH activity of the pituitary gland during different stages of the oestrous cycle. The FsH activity was assayed by the HCG augmentation method in the mouse and the LH activity by the ovarian ascorbic acid depletion method in the rat.

The assays were found to be valid. The results showed that the FsH concentration and the total contents were lowest on the day of oestrus, tended to rise on Day 3, reached a peak level on Days 6 to 9 and then remained more or less constant till Days 15 to 18 . However, the differences between stages were not statistically significant. The overall potency on Days $0,3,6$ to 9,11 to 13 and 15 to 18 was $1.92,3.94,9.45,9.63$ and $8.75 \mu$-equiv. NIH-FSH-s $2 / m g$ 
dried pituitary, respectively. The total contents at the same stages were 289, $674,1219,1639$ and $1502 \mu$ g-equiv. NIH-FSH-s $\mathrm{s}_{2}$ per gland.

The LH concentration or contents in the pituitary also did not vary significantly from one stage to another. However, there was a trend for the LH concentration to be low on Day 3 followed by a continuous increase until Day 11 and then a gradual decrease to a minimum value on Day 15 of the oestrous cycle. The overall relative potency at these three stages was found to be $12 \cdot 49,34.41$ and $11.30 \mu$ g-equiv. NIH-LH-B $3 / \mathrm{mg}$ dried pituitary and the total contents were 2171,4923 and $3797 \mu$ g-equiv. NIH-LH-B $/$ gland, respectively.

It is concluded that both FSH and LH were released some time around oestrus and ovulation and that LH had a biphasic release. It is conjectured that FSH was also associated with the process of ovulation.

A study of follicular and luteal characteristics of the ovary at different stages of the oestrous cycle in the Surti buffalo heifer. G. N. Memon, N. G. Buch and B. M. PAtel, Institute of Agriculture, Anand, Gujarat, India.

In order to examine the nature of follicular and luteal changes in the ovary, forty buffalo heifers of the Surti breed were slaughtered at different stages of the oestrous cycle. Follicular changes were studied on Days 0 (oestrus $=$ Day 0 ), $3,6,9,11,13,15$ and 18 and luteal characteristics estimated at all the above stages except Day 0 during the oestrous cycle.

High values of 0.57 and $0.40 \mathrm{ml}$ for the volume of the fluid in the largest follicle were observed on Days 0 and 11, respectively. The day differences in the follicular volume were statistically significant. The weight of total follicular fluid was high on Days 0,11 and 18 with values of 1479,1640 and $1417 \mathrm{mg}$, respectively and tended to differ significantly with the day of the oestrous cycle. The changes observed suggested that Surti buffalo heifers underwent two growth waves during each cycle. The first peak of follicular activity occurred around the day of ensuing oestrus and the second during midcycle at about Day 11 after oestrus.

Corpus luteum weight rose progressively from $605 \mathrm{mg}$ on Day 3 to $1885 \mathrm{mg}$ on Day 13, followed by a decline to $1292 \mathrm{mg}$ on Day 18. The progesterone concentration was $34.5 \mu \mathrm{g} / \mathrm{g}$ on Day 3 , rising to $62.0 \mu \mathrm{g} / \mathrm{g}$ on Day 13 . The lowest concentration of $32.3 \mu \mathrm{g} / \mathrm{g}$ was observed on Day 18. The total progesterone followed a similar trend, rising from $21.8 \mu \mathrm{g}$ on Day 3 to a maximal value of $116.0 \mu \mathrm{g}$ on Day 13 and subsequently declining to $45.0 \mu \mathrm{g}$ on Day 18 . These data on progesterone content of corpora lutea at various stages of the oestrous cycle should be helpful in understanding the functioning of cyclic corpora lutea in Surti buffalo heifers.

On the rôle of carbonic anhydrase in reproductive processes. $R$. A. Edgren, Karen A. Knudsen and R. G. Jones, Endocrinology Section, Wyeth Laboratories Inc., Philadelphia, Pa., U.S.A.

The rôle of carbonic anhydrase in reproductive processes is incompletely understood despite extensive work over the past 15 years. In 1955, Lutwak-Mann 
showed that this enzyme was found at high levels in the rabbit uterus and that uterine concentration varied with the hormonal state of the animal. Pincus and his associates (1957) adapted these observations to the assay of progestagens, and this work was expanded by Pincus \& Bialy (1963). These two workers also showed that a carbonic anhydrase inhibitor, acetazolamide (Diamox), terminated pregnancy in rats when administered directly into the uterine lumen. Experiments in our laboratory have failed to demonstrate an antipregnancy effect of acetazolamide given systemically to rats, suggesting that the observations of Pincus \& Bialy may have represented a non-specific effect. On the other hand, most experiments have failed to demonstrate a clear effect of ovarian steroids on uterine carbonic anhydrase in rats. In rabbits, the simultaneous administration of progesterone and acetazolamide is associated with an inhibition of uterine carbonic anhydrase rises in the absence of effects on glandular proliferation (Knudsen, Jones \& Edgren, 1971). These data indicate that progesterone-induced carbonic anhydrase is not an obligatory biochemical predecessor of glandular development in rabbit uteri, and suggest the hypothesis that carbonic anhydrase may be a product of endometrial glandular secretion. Preliminary studies show that glandular development precedes the rise in carbonic anhydrase, lending support to the hypothesis.

If this speculation be correct, the functional integrity of the uterus may depend in part upon the production of endometrial carbonic anhydrase by the proliferating or proliferated glands. Thus, specific carbonic anhydrase inhibitors may provide tools for the study of endometrial physiology and may themselves be contraceptive agents when properly employed.

\section{REFERENCES}

Knudson, K. A., Jones, R. C. \& Edgren, R. A. (1971) Endocrinology, (in press).

LuTWAK-MaNn, G. (1955) 7. Endocr. 13, 26.

Pincus, G. \& Bialy, G. (1963) Recent Prog. Horm. Res. 19, 201.

Pincus, G., Miyake, T., Merrill, A. P. \& Longo, P. (1957) Endocrinology, 61, 528.

Influence of drugs on ovarian steroidogenesis in vitro. A model for research in reproductive physiology. J. Hammerstein, Klinikum Stegilitz, 1-Berlin 45, Hindenburgdamm 30, Berlin, Germany.

Pharmacokinetics of contraceptive steroids. K. H. Kimbel, E. Merck, Darmstadt, Germany.

Progestagens and/or oestrogens are taken by many millions of women all over the world for contraceptive purposes. Evidence is accumulating that these steroids, at the doses and schedules given, may interfere with several physiological processes. Recent data indicate that lowering of the dose and modification of the mode of administration may alleviate most, if not all, of these undesirable side effects. Among others, four ways to reach a minimal dose of a contraceptive steroid seem to be feasible:

(a) Achievement of complete enteral or parenteral absorption.

(b) Full usage of the whole duration of action.

(c) Concentration of the steroid at the site of action.

(d) Economization of dosage by maintaining a constant tissue level by means 
of repository effects. This would, in addition, allow the administration of the steroids at intervals greater than 1 day, thus reducing failures due to missed intake and offer the possibility of administration supervised by the physician or paramedical personnel.

All four ways require a profound knowledge of the absorption, distribution and excretion of the steroids used in hormonal contraception, but a review of the literature shows that there are practically no quantitative data on the fate of the original steroid in the human body. Most figures on absorption from the intestine or injection side, blood and tissue levels and excretion are based on the radioactive label and it is uncertain whether these relate to the original compound or its metabolites which may or may not be biologically active. The fact that the biological half-life of the label, which is probably still attached to the steroid nucleus, exceeds the dosage interval in a good number of contraceptive steroids used should be further investigated. It would also be of interest to localize the site of deposition and the availability and biological activity of steroids stored away. Finally, it seems to be promising to study the organ distribution of various steroid derivatives in human beings in order to find compounds with an affinity for certain compartments and target organs in order to reduce the distribution volume and consequently the drug dosage.

Evaluation of gonadotrophin analyses in male hypogonadism. S. G. Johnsen, Male Hypogonadism Study Section, Medical Outpatients' Department, University Hospital of Copenhagen, and from the Hormone Department, Statens Seruminstitut, Copenhagen, Denmark.

Urinary total hypophysial gonadotrophin (HG) analyses in fifty-six healthy men and 282 patients with a great variety of forms of male hypogonadism showed that, in some clinical conditions, $\mathrm{HG}$ is decreased, in others increased and in still others the HG level is normal. However, this information tells little about the hypophysial function in the disorders because the HG level depends entirely upon the functional state of the germinal epithelium.

By the testicular biopsy score count method described by the author, a figure (mean score, MS) is obtained which expresses the spermatogenic state. Analysis of 284 patients with primary testicular disorders established the correlation between the $\log$ gonadotrophin value (log HG) and MS. It was found that the HG level in the control group of apparently healthy men was considerably higher than that corresponding to perfect spermatogenesis. The question whether 'ideal' men with perfect spermatogenesis or 'average healthy' men should be used as controls in gonadotrophin assays is a dilemma.

By using the regression equation between $\log$ HG and MS, the influence of various spermatogenic states upon the HG level was eliminated by transforming, in each patient, the log HG value to the value corresponding to a fixed MS of $1 \cdot 0$. These transformed log HG values in the various disorders were then analysed. Decreased values were found in hypopituitarism, infantilism, eunuchoidism, adiposo-genital dystrophy (in adults) and hypogonadism secondary to metabolic disease. In all other conditions, the HG level corresponded to the spermatogenic state. No extratubular factors seem to 
influence the HG level and no condition of primary over-production of gonadotrophins was found.

The value of transforming gonadotrophin values to a defined spermatogenic state in clinical and experimental studies is discussed.

Pituitary functions as judged by urinary excretion of FSH and $\mathrm{LH}$ in normal married young women cyclically treated with $0.5 \mathrm{mg}$ megesterol acetate. Subhas MukerjI, N.R.S. Medical College, Calcutta, India.

Using specific biological assay procedures, FSH and LH excretion was measured in two normally menstruating young subjects before, during and after administration of megesterol acetate from the 5th to the 25th day of the cycle. Urinary excretion of 'total oestrogen' was also estimated.

The laboratory data and the results of the preliminary clinical trial regarding the reproductive performance of the subjects are discussed.

Function of the human ovary during pregnancy as revealed by the histochemical, biochemical and electron microscope techniques. S. S. GuRaya, Department of Zoology, University of Udaipur, Rajasthan, India.

The function of the human ovary during pregnancy has been determined by correlating the results of histochemical, biochemical and electron microscope studies on the ovarian compartments such as follicle, corpus luteum and interstitial gland tissue, which are exposed to an unusual steroidal and gonadotrophic environment. The cytological, histochemical and biochemical features of the theca interna cells of developing follicles, the theca lutein and granulosa lutein cells of the corpus luteum and the highly developed interstitial gland cells during the later stages of pregnancy have suggested that they constitute the sites for the biosynthesis of steroid hormones, and their function must be the secretion of steroid hormones rather than the storage of hormone precursors (steroidal lipids) as a result of high levels of HCG; the latter has also been shown by Savard and his co-workers to be capable of stimulating steroidogenesis in vitro in the various compartments of the human ovary. This has been strongly supported by the direct analysis of multiple steroid secretions collected from the ovarian vein during pregnancy.

Besides the hypertrophied theca interna, theca lutein, granulosa lutein and interstitial cells (which are active steroid secretors), many cells are seen with foamy cytoplasm filled with lipids. They are the senescent cells which are refractory to gonadotrophic substances available in abundance during pregnancy.

It is suggested that further comparative studies of morphological and biochemical responses of ovarian compartments as well as of their steroidal secretions during pregnancy are of considerable biological interest and form a most promising area for future research.

Clinical trial with continuous low dosage $(0.5 \mathrm{mg})$ chlormadinone acetate. Shanti M. Shahani and Manjari K. Munsif, Department of Endocrinology, T. N. Medical College and Nair Hospital, Bombay-8, India.

Chlormadinone acetate $(0.5 \mathrm{mg})$ was given continuously to 200 patients for 
1512 cycles over a period of 2 years. The women were in the reproductive age group and of proved fertility. Lack of cycle control was the chief drawback. However, the majority of the cycles were of normal duration, intensity and flow. Breakthrough bleeding occurred in $3.8 \%$ of the total cycles. Forty-nine percent of the patients had side effects in $18.6 \%$ of the total cycles. They were common in the first 3 months but were mild. No pregnancy occurred due to method failure. Six pregnancies occurred due to tablet omission on 2 or more days. A heavy drop-out rate of $78.5 \%$ was found. The majority of the patients dropped out for reasons not related to the drug; $14 \%$ of the patients dropped out because of side effects of the drug. Vaginal cytohormonal study, premenstrual endometrial biopsies and postcoital tests were carried out during the trial to study the mode of action of the drug.

Long-acting injectable therapy for fertility control. K. D. VIRKAR, S. J. Kora, S. S. Dikshit and M. J. Lodaya, Contraceptive Testing Unit (ICMR), Bombay-12, India.

Clinical trials of 1 year's duration with injectable Depo Medroxy progesterone acetate (150 mg) every 3 months with diethyl stilboestrol tablets $(1 \mathrm{mg})$ every 7 days in a month were carried out in 272 women.

A total of 1111 cycles was studied. It was found that the menstrual pattern was changed leading to irregular cycles and amenorrhoea. Of the cycles studied, $60.5 \%$ were normal while, in $6.2 \%$ of the cycles, the interval between two cycles was more than 66 days; $5.5 \%$ of the cycles were prolonged and heavy. Breakthrough bleeding occurred in only $19.7 \%$ of the cycles.

Common side effects of oral contraceptives were virtually absent but gain in weight and increase in blood pressure were noted.

The therapy was effective as no pregnancy occurred with 2175 months of use.

No significant change in cytology was noticed during the clinical trials.

Blood pressure with hormonal contraception. S. S. Dikshit and K. D. Vrrkar, Contraceptive Testing Unit, CVTC Building, Parel, Bombay-12, India.

Blood pressure readings were studied in 1356 women taking hormonal contraceptives. Fifty-three cases $(3.9 \%)$ showed an increase of blood pressure.

The parameters of age, parity, previous history of pregnancy toxaemia or hypertension are considered.

An attempt is made to differentiate the effect of different types of steroids and the duration of therapy.

In twenty-one cases, therapy was stopped because of an increase in blood pressure; in seventeen of these, blood pressure then returned to the pretreatment level, in one case it decreased but not to the level observed initially, while three cases could not be followed up.

Rise of blood pressure on a hormonal basis is discussed. 
Action of growth-promoting hormones on membrane function and gene locus. G. P. Talwar, Department of Biochemistry, All India Institute of Medical Sciences, New Delhi, India.

Studies on the in vitro formation of monoiodotyrosine by soluble supernatant of pigeon thyroid gland. SAMIR BHATtACHARYA and AsHoK G. DAtTA, Department of Physiology, Indian Institute of Experimental Medicine, Calcutta-32, India.

Soluble supernatant preparation of pigeon thyroid gland can catalyse the iodination of tyrosine to monoiodotyrosine in vitro. The enzyme needs a hydrogen peroxide generating system such as glucose and glucose oxidase or $\mathrm{Cu}^{++}$ for its activity. Optimum concentration of $\mathrm{Cu}^{++}$was found to be $1.33 \times 10^{-3} \mathrm{M}$. The requirement of $\mathrm{Cu}^{++}$cannot be substituted by direct and slow addition of hydrogen peroxide. Antithyroid agents like thiourea and thiouracil are found to be more potent as inhibitors of avian enzyme than mammalian enzyme. Ascorbic acid inhibits the enzyme but stimulates remarkably when a dialysed enzyme is used instead of an undialysed one. Addition of concentrated dialysate causes abolition of ascorbate stimulation of dialysed enzyme. Data suggest that on dialysis a factor is removed from the enzyme preparation which is responsible for the abolitition of ascorbate stimulation. The factor seems to be a low molecular protein since it is dialysable and boiling for $3 \mathrm{~min}$ and treatment with trypsin and chymotrypsin destroys its activity. The factor gives a positive reaction with Folin's phenol reagent as well as ninhydrin and, when eluted from a chromatogram after paper chromatography, abolishes the ascorbate stimulation of dialysed enzyme.

Comparison of the effects of methallibure and thiourea on the testis, thyroid and adenohypophysis of the adult and juvenile guppy, Poecilla reticulata Peters. S. Pandey and J. F. Leatherland, Department of Zoology, University of Patna and Department of Zoology, University of Hull, England.

Thiourea and methallibure are equally effective in completely blocking the initiation of spermatogenesis in juvenile guppies and also in inhibiting spermatogenesis in adults. Both compounds appear to act by blocking the activity of pituitary gonadotrophs which regress.

Although methallibure has goitrogenic effects in adult guppies, these effects are far less pronounced than those of thiourea which are apparent in both adult and juvenile fishes.

Whereas thiourea inhibits growth and causes an increase in granulation in the pituitary somatotrophs, methallibure causes a degranulation of the somatotrophs, a depression of the somatotroph cell index (in adults) and does not significantly affect the growth rate.

Gynaecography as a diagnostic aid in infertility. V. GoyAL, P. K. Malkani, R. K. Narula and S. Bhargava, Departments of Obstetrics and Gynaecology and Radiology, All India Institute of Medical Sciences, Nerw Delhi-16, India.

Complete gynaecography with the Foley catheter technique was performed in 
fifty-four patients. Ten women with proved fertility and forty-four women complaining of infertility were studied. The use of the Foley catheter was found to be satisfactory.

The uterus and ovaries were measured. The uterine index, ovarian index and ovario-uterine ratio were calculated.

The ovarian area was increased in cases of the polycystic ovary syndrome as compared with the control group.

The width and thickness of the uterus were less in patients with the polycystic ovary syndrome as compared to normal women. This difference was statistically significant.

In women with amenorrhea, the width of the uterus was smaller than in normal women but the difference in the thickness of the uterine wall was not statistically significant.

The ovario-uterine ratio was more reliable than the area of the ovaries as an index of the diagnosis of the polycystic ovary syndrome.

Effect of daily single-dose corticoid therapy on the pituitary-ovarian axis: a preliminary report. L. Kumari, Somnath Roy, S. Kumar and I. S. Allag, Medical Education and Research Division, Central Family Planning Institute, New Delhi-16, India.

Roy, Narula \& Malkani (1968) have shown that administration of glucocorticoid once daily, at about midnight, to anovulatory women induces ovulation in some selected groups of patients. The object of such therapy is to suppress the early morning surge of ACTH release from the pituitary and thereby to inhibit the secretion of abnormal sex steroids from the adrenal cortex thus relieving the pituitary-gonadal axis and permitting the release of gonadotrophin. To test this hypothesis further, urinary oestrogens have been measured in the present study before and during oral administration of $0.5 \mathrm{mg}$ of dexamethasone daily at about midnight, over a period of 3 months. Six anovulatory women received such treatment and urinary oestrogens, oestrone, oestradial and oestriol, were measured by fluorimetric analysis during the control period and again at 1,2 and 3 months after the initiation of therapy.

In five out of six cases a definite increase in the total oestrogen excretion was noted during corticoid therapy. In two of them, the rise was noticed at the end of a month; in the other two, by the end of the 2nd month and in the fifth case at the end of the 3rd month. Oestrogen levels registered an initial fall in the 1st month in two cases and in the 1st and 2nd months in another. In the sixth case, the oestrogen level showed a fall at the end of the 1st and 2nd months and returned to the original level at the end of the $3 \mathrm{rd}$ month. The significance of these findings is discussed.

\section{REFERENCE}

Rox, S., Narula, R. K. \& Malkant, P. K. (1968) F. Obstet. Gynaec., India, $18,1$.

Premature menopause. Pratibha R. Vaidya and V. N. Purandare, K. E. M. Hospital, Bombay-12, India.

Premature menopause is an important condition to be excluded before treating 
the patient for amenorrhoea or oligomenorrhoea with the new ovulating drugs such as clomiphene citrate and gonadotrophic hormones.

The present article reports four cases of this syndrome. Three of these were diagnosed by ovarian biopsy and one patient was diagnosed by the high gonadotrophin concentrations in the urine.

Joint action of clomiphene citrate and human pituitary gonadotrophins. A. G. Grooke, Merroo Hansotia* and P. V. Bertrand, Department of Clinical Endocrinology, Birmingham and Midland Hospital for Women, Showell Green Lane, Sparkhill, Birmingham, England, and *T11, Cusrow Baug, Fort, Colaba Causeway, Bombay-1, India.

During the course of sensitivity tests, eighteen patients were treated at different times with the same dosages of FSH and HCG with and without clomiphene citrate. Nine out of fifteen patients who provided sufficient data for analysis were given dosages of FSH which were, on average, $40 \%$ of the minimum effective dose. None responded to this treatment (as judged by oestriol and pregnanediol). Six others were given dosages which were, on average, $72 \%$ of the minimum effective dose of FSH. All responded to combined treatment with gonadotrophins and clomiphene citrate but only three responded to gonadotrophin alone. In these six cases, clomiphene augmented the activity of FSH by a factor of $173 \%$ (95\% fiducial limits 101 to $788 \%$ ).

Fertilization. R. G. Edwards, Physiological Department, University of Cambridge, England.

Effects of erythro-MEA on the female reproductive tract. K. W. Humphrey, Department of Veterinary Physiology, University of Sydney, N.S.W., Australia.

Assay of HCG by biological and immunological methods. Shanta S. Rao, Vijaya P. Raghavan, Tarala V. Purandare and A. R. Sheth, Institute for Research in Reproduction, Jehangir Merwanji Street, Parel, Bombay-12, India.

Semi-quantitative estimation of human chorionic gonadotrophin in urine by immunological and biological assays during pregnancy. Shanti M. Shahani and Pramila V. Dandekar, Department of Endocrinology, T. N. Medical College and Nair Hospital, Bombay-8, India.

The use of the slide immunological and rat ovarian hyperaemia tests for the semi-quantitative determination of HCG activity in urine is discussed.

The slide immunological test is simple, rapid and reliable. Its use, along with the concentration technique, is described.

The mean HCG titres observed in fifty-six samples of normal pregnancy urine are presented. The peak level of activity was observed between 60 and 70 days after the last menstrual period. 
The biological test ran parallel to the immunological test but the end point was at one dilution higher in both normal and abnormal pregnancy.

The use of the semi-quantitative method for assessing HCG activity in pathological conditions is suggested.

Hormonal control of gestation in the intact rat. Studies using specific antigonadotrophins. H. G. MADHWA RAJ and N. R. Moudgal, Endocrinology Laboratory, Department of Biochemistry Indian Institute of Science, Bangalore-12, India.

Investigations on the trophic hormone control of pregnancy in the rat have made use of the hypophysectomized animal. These studies have shown prolactin to be the luteotrophic hormone in that it maintains the luteal structure and is responsible for progesterone synthesis. However, studies in vitro have clearly shown that $\mathrm{LH}$ is responsible for progesterone synthesis per se. In this study, a specific FSH inhibitor isolated from the urine of the bonnet monkey has been used, together with well characterized antisera to ovine FSH and LH to neutralize selectively one or other hormone activity in the intact pregnant rat. Inhibition of FSH had no effect on the course of gestation in the rat but selective neutralization of LH before Day 4 inhibited ovo-implantation, mainly by inhibiting the oestrogen surge. Using a minimum effective dose of the antiserum, delayed asynchronous implantation has been demonstrated. Neutralization of endogenous LH in the postimplantation stages, on any day up to Day 12, resulted in termination of pregnancy. Neutralization of LH even for $2 \mathrm{hr}$ was deleterious for foetal survival. These effects could be specifically reversed by LH or progesterone, but not by ovine or murine prolactin, or by oestrogen. These results demonstrate the control of oestrogen and progesterone synthesis by LH in the intact pregnant rat. The antiserum was not effective in terminating pregnancy when given on or after Day 12. All three gonadotrophins-FSH, LH and prolactin-and the three steroids-progesterone, 20- $\alpha$-hydroxyprogesterone and oestrogen-were tested for their progestational activity in vivo using the postponement of parturition as the index. Only LH among the gonadotrophins, and progesterone among the steroids, could prolong gestation and inhibit parturition.

The results of our studies have been integrated with the findings of other investigators and a model for the hormonal control of gestation in the intact rat has been proposed. LH has been given the rôle of the steroidogenic hormone in the model and a feedback inhibition of LH by circulating steroids at midpregnancy has been proposed. Prolactin has been given a dual rôle in the model: (a) to synergize with $\mathrm{LH}$ in maintaining the precursor pools in the corpus luteum to facilitate a constant steroid output, and (b) to prevent the progesterone synthesized from being catabolized to 20- $\alpha$-hydroxyprogesterone, which is very much less active. Thus, it is proposed that successful maintenance of gestation in the intact rat is achieved by a combination of both LH and prolactin acting optimally on the corpus luteum. The trophic control of the structural and functional integrity of the corpus luteum in relation to the luteotrophic process during gestation is discussed. 
An immunochemical study of ovine pituitary follicle-stimulating hormone. A. Jagannatha Rao and N. R. Moudgal, Department of Biochemistry, Indian Institute of Science, Bangalore, India.

Immunochemical studies have been carried out with ovine pituitary FSH and its antibody produced in rabbits. Using the precipitin technique, it has been shown that although antiserum to NIH ovine FSH gives five precipitin bands in the agar gel diffusion test, none of them is specific for ovine FSH. All the precipitin bands are due to contaminating antigens which accompany FSH during fractionation from the pituitaries. Further, studies using the agglutination and complement fixation techniques have revealed that FSH, being a univalent antigen, forms a soluble complex with its specific antibody. This data is also supported by the biological assays and gel filtration on Sephadex using ${ }^{125}$ I-labelled FsH. Using FSH antiserum free of LH antibody, it has been possible to show that ovine FSH antiserum is species non-specific in that it is able to neutralize the FSH activity of rat, mouse, hamster and guinea-pig pituitary extracts and also PMSG. Similar results have been obtained using an antiserum produced in the guinea-pig to a highly purified preparation of ovine FsH. A study of the HGGFSH antibody interaction has shown that HCG does not form a complex with FSH-specific antibody.

Primary immune response of rats and rabbits treated with Enovid. Shanta S. Rao and Usha M. Joshi, Division of Fundamental Research, Institute for Research in Reproduction (ICMR), Jehangir Merwanji Street, Parel, Bombay-12, India.

The effect of the contraceptive agent Enovid on the primary immune response of the rat and the rabbit was studied. Two dose levels were employed in the rat, one corresponding to twice the human dose based on $\mathrm{mg} / \mathrm{kg}$ body weight and the other equivalent to twenty times the human dose. In the rabbit, only twenty times the human dose was given. The immune response was assessed by determining the haemagglutinin and haemolysin titres in the sera of these animals after treatment for 4 months. Enovid was observed to cause a slight diminution in the immune response of the rat. Large variations in the responses of rabbits from the same group made comparison difficult. The reasons for the change in the immune response of rats are discussed.

Effect of Ovulen and Depo-Provera on primary and secondary immune response in mice and rats. UsHa M. JOSHI, KISHORI N. RANGNEKAR and Shanta S. Rao, Reproductive Physiology Unit, G. S. Medical College, Bombay-12, India.

Two contraceptive steroidal preparations were screened to investigate their effect on the formation of circulating antibodies in laboratory animals.

Ovulen was administered orally while Depo-Provera was injected parenterally into mice and rats. The titres of antibodies were determined after primary and secondary immunization with sheep erythrocytes. The preparations screened did not significantly alter the immunological response of the treated animals. 